\title{
Generation of Political Priority for Global Health Initiatives: A Framework and Case Study of Maternal Mortality By Jeremy Shiffman and Stephanie Smith
}

\begin{abstract}
Why do some global health initiatives receive priority from international and national political leaders while others receive minimal attention? We propose a framework for analyzing this question consisting of four categories of factors: the strength of the actors involved in the initiative, the power of the ideas they use to frame the issue, the nature of the political contexts in which they operate, and characteristics of the issue itself.

We apply this framework to the case of a global initiative to reduce maternal mortality, launched in 1987. Using a process-tracing methodology commonly employed in qualitative research, we conducted archival research and interviewed actors involved in the initiative. We find that despite two decades of effort the initiative remains in an early phase of development, hampered by difficulties in all these categories. However, the initiative's twentieth anniversary year, 2007, presents opportunities to build political momentum. To generate political priority advocates will need to address several challenges, including the creation of effective institutions to guide the initiative and the development of a public positioning of the issue that convinces political leaders to act.

We draw on the framework and case study to suggest areas for future research on the determinants of political priority for global health initiatives, a subject that has attracted much speculation but little scholarship.
\end{abstract}

The Center for Global Development is an independent think tank that works to reduce global poverty and inequality through rigorous research and active engagement with the policy community. Use and dissemination of this Working Paper is encouraged, however reproduced copies may not be used for commercial purposes. Further usage is permitted under the terms of the Creative Commons License. The views expressed in this paper are those of the author and should not be attributed to the directors or funders of the Center for Global Development. This working paper was originally published in The Lancet, Volume 370, October 13, 2007. 


\section{Generation of Political Priority for Global Health Initiatives: A Framework and Case Study of Maternal Mortality}

Published in The Lancet, Volume 370, October 13, 2007

http://www.thelancet.com

Jeremy Shiffman, Ph.D.

Associate Professor of Public Administration

The Maxwell School of Syracuse University

306 Eggers Hall

Syracuse, NY 13244-1020 USA

jrshiffm@maxwell.syr.edu

Stephanie Smith, Ph.D. candidate Department of Public Administration

The Maxwell School of Syracuse University

306 Eggers Hall

Syracuse, NY 13244-1020 USA

slmit05@maxwell.syr.edu 


\section{INTRODUCTION}

Global health initiatives vary in the level of political priority they receive from international and national leaders. Child immunization, family planning and HIV/AIDS, for instance, at certain points have attracted considerable resources, while malnutrition and pneumonia have received minimal attention despite also addressing high burden conditions. W e know little about the sources of variance in priority levels afforded to global health initiatives, as there is a lack of systematic research on the subject.

We draw on scholarship on collective action to propose an initial framework for analyzing the determinants of political priority for global health initiatives, one we hope future researchers will modify and improve. It consists of four categories of factors: the power of involved actors, the ideas they use to position the issue, the nature of the political contexts in which they operate, and characteristics of the issue itself. ${ }^{i}$ We apply this framework to the global safe motherhood initiative, launched in 1987 to reduce maternal mortality levels. Safe motherhood is a revealing case since it reached its twentieth anniversary in 2007, but despite determined efforts by advocates, as of that year had yet to attract the level of political attention its founders hoped it would receive.

A global initiative is an organized effort linking actors across national borders to address an issue of international concern, such as climate change or human rights. Global political priority is the degree to which international and national political leaders actively pay attention to an issue, and back up that attention with the provision of

\footnotetext{
${ }^{\mathrm{i}}$ A recently published study on political priority for maternal mortality reduction, complementary to this one, took the country as the unit of analysis and developed a framework that sought to explain variance in levels of national priority for safe motherhood in Guatemala, Honduras, India, Indonesia and Nigeria. ${ }^{1}$ This study asks a similar question concerning variance in political priority levels, but with the global health initiative as the unit of analysis. It deepens and expands the first framework by grounding it in the extensive research on collective action.
} 
financial, technical and human resources commensurate with the problem's severity. We know global political priority is present when: (1) international and national political leaders publicly and privately express sustained concern for the issue; (2) the organizations and political systems they lead enact policies to address the problem; and (3) these organizations and political systems devote levels of resources to the problem commensurate with its gravity. These three conditions include not only international but also national components, since global initiatives rarely hold the aim of only generating priority among international organizations; they also seek political support from national political systems.

By itself global political priority is not sufficient to address an international problem successfully. Effective policies, technology and implementation systems, among other elements, are also critical. However, global political priority is a facilitating condition for success, and therefore crucial to investigate.

In the sections that follow, we present the framework, examine determinants of global political priority for safe motherhood with reference to this framework, point to challenges the initiative may face in building priority over the coming decade, and identify questions for future research on sources of political priority for global health initiatives.

\section{THE FRAMEWORK}

Researchers have sought to understand why initiatives pursuing social and political change succeed or fail in attracting political support. They have investigated several kinds of collective action efforts, including international networks on issues such as climate change, ${ }^{2-6}$ social movements for causes such as civil rights ${ }^{7-10}$ and policy communities that aim to place particular issues on national agendas ${ }^{11-13}$. A central 
concern in collective action research is the role of power: the power of actors involved with the issue; the power of the ideas used to define and describe the issue; the power of political contexts to inhibit or facilitate political support; and the power of certain characteristics of the issue, such as the number of deaths a particular disease may cause, to inspire action. ${ }^{\text {ii } 2-13}$

These four elements - the power of actors, the influence of ideas, the nature of political contexts and characteristics of the issue itself - form the foundation of our framework on the determinants of political priority for global initiatives (table 1). Initiatives are more likely to attract political support if they share certain features in each category.

The first element is actor power. Initiatives differ in the strength of the actors that compose them, in the quality of linkages among these actors, and in the collective capacity of the actors to confront opponents. ${ }^{14-16}$ Among the actors that influence initiative acquisition of political support are policy communities (factor 1), the network of individuals and organizations who operate at the global level and are linked by a central concern for the issue. These communities include, among others, prominent NGO leaders, government officials, bilateral donors, members of UN agencies, other international organizations and academics. Policy communities that agree on basic issues such as how the problem should be solved are more likely to acquire political support than those divided by such issues, as politicians will be more likely to listen to the former as authoritative sources of knowledge. The emergence of respected leaders embraced by the community (factor 2) facilitates coalescence and gives direction to the initiative.

\footnotetext{
ii Each of the several research traditions concerned with collective action examines the power of actors, ideas, political contexts and issue characteristics. However, the traditions use different terms for similar concepts. For instance, when referring to the power of ideas, social movement theorists often use the term 'framing processes ${ }^{10}$, international relations scholars speak of 'strategic social construction' ${ }^{3}$ and public policy scholars write about 'policy images ${ }^{13}$. All refer to the same basic concept: the way in which actors concerned with a problem position it publicly.
} 
UNICEF's former director James Grant, for instance, is often cited as an example of such a leader. Strong guiding institutions (factor 3) - organizations or coordinating mechanisms with a mandate to lead the initiative - are also critical. Initiatives may start through informal associations or as projects inside formal organizations, but if they are to thrive, they must build their own enduring institutions. ${ }^{7}$ Ongoing competition among concerned organizations to control the issue may hamper the creation of these structures. The Task Force for Child Survival and Development formerly led by Grant has been noted as a particularly effective guiding institution for the cause of child health. Finally, initiatives are more likely to generate political support if they link with grassroots organizations in civil society pushing for global attention to the issue (factor 4), rather than remain confined to select members of a global policy community. Pressure from grassroots AIDS activists on national governments and on international organizations, for instance, has helped to increase donor aid to address the disease in developing countries. Ideas also shape political support for initiatives. The role of ideas in politics has inspired considerable research, ${ }^{4,17}$ grounded in recognition that material influences alone cannot explain all actor behavior and that actors interpret the world around them in very different ways. The central ideational variable in collective action research is the 'frame': the way in which an issue is understood and positioned publicly. ${ }^{10}$ Any issue can be framed in multiple ways. For instance, HIV/AIDS has been framed as a public health problem, a development issue, a humanitarian crisis and a threat to security. ${ }^{18-19}$ Some frames resonate more than others, and different frames appeal to different audiences. Finance ministers, for instance, may be more likely to respond to frames that emphasize the economic costs of a health problem, while health ministers may pay more attention to frames that focus on public health benefits and losses. Frames that resonate internally (factor 5) unify policy communities by providing a common understanding of the definition of, causes of and solutions to the problem. Frames that resonate externally 
(factor 6) move critical audiences to action, particularly the political leaders who control the resources that initiatives need.

The political contexts in which actors operate also exert considerable influence on political support levels. ${ }^{20-23}$ Actors may have little control over these contextual factors, but they must take them into account if they wish to develop effective strategies. Many elements of political context matter, but two are key. First are policy windows (factor 7). These are moments in time when global conditions align favorably for an issue, presenting advocates with particularly strong opportunities to reach international and national political leaders. ${ }^{12}$ Policy windows often open following major disasters (such as a tsunami), discoveries (a new vaccine) or forums (global UN conferences). The Millennium Development Goals, for instance, have facilitated the opening of policy windows for some of the causes included. A second critical element of context is the global governance structure for the sector (factor 8) - the set of norms (shared beliefs on appropriate behavior) and the institutions that negotiate and enforce these norms. International treaties, laws and declarations exist for many sectors, including trade, the environment and health, often with an international organization or set of organizations in charge of their enforcement. In some sectors, these structures work well; in others, they are dysfunctional. Several studies have expressed concern about the increasingly fragmented structure of global governance for health, with many organizations competing for power, constantly shifting priorities and no single organization or set of organizations with the power to coordinate. ${ }^{24-25}$

Finally, the nature of the issue itself shapes political priority. Some issues are intrinsically easier to promote than others. ${ }^{2,26}$ Problems easily measured are more likely to gain political support than ones that are not, as policy-makers and advocates will have information to confirm the severity and monitor progress (factor 9). For instance, studies providing credible evidence of high population growth and fertility rates interacted with 
other factors in the 1970s and 1980s to convince political leaders in many developing countries that they had population problems requiring attention. Problems that cause significant harm, as indicated by objective measures such as numbers of deaths, are more likely to attract resources than those that do not, as policy-makers will perceive the former as more serious (factor 10). Problems with relatively simple, inexpensive, evidence-based solutions will be easier to promote than those without these features, as policy-makers prefer to devote resources to issues that they think they can address effectively and cheaply (factor 11). Cheap and effective vaccines, for instance, have helped generate political attention for child immunization.

No factor is likely necessary or sufficient for political support: some initiatives that have not attracted political priority possess a number of these characteristics and some initiatives that have received political attention lack several. For instance, HIV/AIDS presently attracts considerable political support despite extensive contention within its global policy community, and polio eradication continues to receive substantial resources despite the disease's small global burden compared to many other conditions. Conversely, chronic diseases such as cardiovascular conditions, cancer and diabetes, certain communicable diseases such as pneumonia, and a number of risk factors such as malnutrition attract few global resources despite causing high morbidity and mortality. Cases such as these point to the need for ongoing research on the determinants of political priority for global health initiatives, including assessment of the relative causal weights of the factors, their interactive effects, and whether different combinations of factors may lead to issue ascendance in global health.

These cases notwithstanding, existing research on collective action provides evidence that, other things being equal, each factor enhances the likelihood an initiative will receive priority. A global policy community is more likely to generate political support for its concern if it is cohesive, well-led, guided by strong institutions and backed 
by mobilized civil societies; if it agrees on solutions to the problem and has developed frames for the issue that resonate with political leaders; if it takes advantage of policy windows and is situated in a sector with a strong global governance structure; and if it addresses an issue that is easily measured, high in severity and has effective interventions available. In such a situation, actor power, ideas, political contexts and issue characteristics all work in favor of the initiative.

Table 1: Framework on determinants of political priority for global initiatives

\begin{tabular}{|c|c|c|}
\hline Category & Description & Factors shaping political priority \\
\hline \multirow[t]{4}{*}{ Actor power } & \multirow{4}{*}{$\begin{array}{l}\text { The strength of the } \\
\text { individuals and } \\
\text { organizations } \\
\text { concerned with the } \\
\text { issue }\end{array}$} & $\begin{array}{l}\text { 1. Policy community cohesion: The degree of coalescence among the } \\
\text { network of individuals and organizations centrally involved with the } \\
\text { issue at the global level }\end{array}$ \\
\hline & & $\begin{array}{l}\text { 2. Leadership: The presence of individuals capable of uniting the policy } \\
\text { community and acknowledged as particularly strong champions for } \\
\text { the cause }\end{array}$ \\
\hline & & $\begin{array}{l}\text { 3. Guiding institutions: The effectiveness of organizations or } \\
\text { coordinating mechanisms with a mandate to lead the initiative }\end{array}$ \\
\hline & & $\begin{array}{l}\text { 4. Civil society mobilization: The extent to which grassroots } \\
\text { organizations have mobilized to press international and national } \\
\text { political authorities to address the issue at the global level }\end{array}$ \\
\hline \multirow[t]{2}{*}{ Ideas } & \multirow[t]{2}{*}{$\begin{array}{l}\text { The ways in which } \\
\text { actors understand and } \\
\text { portray the issue }\end{array}$} & $\begin{array}{l}\text { 5. Internal frame: The degree to which the policy community agrees on } \\
\text { the definition of, causes of and solutions to the problem }\end{array}$ \\
\hline & & $\begin{array}{l}\text { 6. External frame: Public portrayals of the issue in ways that resonate } \\
\text { with external audiences, especially the political leaders who control } \\
\text { resources }\end{array}$ \\
\hline \multirow[t]{2}{*}{$\begin{array}{l}\text { Political } \\
\text { contexts }\end{array}$} & \multirow[t]{2}{*}{$\begin{array}{l}\text { The environments in } \\
\text { which actors operate }\end{array}$} & $\begin{array}{l}\text { 7. Policy windows: Political moments when global conditions align } \\
\text { favorably for an issue, presenting opportunities for advocates to } \\
\text { influence decision-makers }\end{array}$ \\
\hline & & $\begin{array}{l}\text { 8. Global governance structure: The degree to which norms and } \\
\text { institutions operating in a sector provide a platform for effective } \\
\text { collective action }\end{array}$ \\
\hline \multirow[t]{3}{*}{$\begin{array}{l}\text { Issue } \\
\text { characteristics }\end{array}$} & \multirow[t]{3}{*}{$\begin{array}{l}\text { Features of the } \\
\text { problem }\end{array}$} & $\begin{array}{l}\text { 9. Credible indicators: Clear measures that demonstrate the severity of } \\
\text { the problem and that can be used to monitor progress }\end{array}$ \\
\hline & & $\begin{array}{l}\text { 10. Severity: The size of the burden relative to other problems, as } \\
\text { indicated by objective measures such as mortality levels }\end{array}$ \\
\hline & & $\begin{array}{l}\text { 11. Effective interventions: The extent to which proposed means of } \\
\text { addressing the problem are clearly explained, cost-effective, backed } \\
\text { by scientific evidence, simple to implement, and inexpensive }\end{array}$ \\
\hline
\end{tabular}

\section{METHODS}


To examine the global safe motherhood initiative we used a methodology commonly employed in qualitative social science inquiry, process-tracing, involving analysis of multiple sources of information in order to uncover social processes and evaluate causality. ${ }^{27}$ In 2005, 2006 and 2007 we conducted 23 interviews, lasting on average one and a half hours, with individuals centrally involved in the development of the global initiative, including most of its founders. Each has worked on safe motherhood with a United Nations agency, multilateral financial institution, university or international non-governmental organization. We drew also on data from a complementary study on political priority for maternal mortality reduction in five developing countries, which included interviews with bilateral donors, national political officials and national NGO leaders. ${ }^{1}$ In addition, we undertook archival research on the history of the initiative, collecting and reviewing more than seventy documents from coordinating organizations for the initiative, donors, UN agencies, NGOs and other actors. Beyond this, we consulted scholarly literature on maternal mortality and the safe motherhood initiative. Once we had collected the material, we reviewed the interview transcripts, documents and scholarly literature to analyze factors that shaped political priority for the initiative. One of our aims was to capture the perspectives of global safe motherhood actors themselves on the state of political priority for the initiative. We therefore draw heavily on excerpts from the interviews in presenting our data.

We provided a draft of the paper to many of the interviewees, and incorporated feedback they provided. We also distributed and presented the paper at a MacArthur Foundation-organized consultation in May 2007 on global safe motherhood strategy, attended by 24 individuals connected to the initiative. We revised the draft based on feedback from a number of participants who attended the meeting.

We take no stand on the technical debates surrounding appropriate intervention and measurement strategies that have emerged in the initiative. ${ }^{28-30}$ Our aim rather is to 
examine the content of these debates and how they were understood by the participants themselves to assess the influence the debates had on political support for the initiative. Also, our focus is on the initiative's global rather than national or grassroots level actors and debates, except in those instances when national and grassroots actors have influenced or been influenced by the global safe motherhood initiative. National and community experiences, and the perspectives and voices of actors from the South, are critical dimensions of the history of safe motherhood and deserve research attention (see bibliographic notes 31-36 for studies of this kind) ${ }^{31-36}$ This case study, however, limits itself to examining developments surrounding the global safe motherhood initiative.

A limitation of our case study methodology is the difficulty in controlling for confounding variables of influence, and in assessing the relative causal weight of factors that we identified as shaping political priority. As we note above, this study must be taken as an initial exploration of the complex question of issue ascendance and neglect in global health. Considerably more research, ideally comparing global health initiatives varying in political support levels, will be necessary to determine which factors are more and less influential in shaping political priority.

\section{THE CASE OF SAFE MOTHERHOOD}

In 1987 the World Bank, the World Health Organization (WHO) and the United Nations Population Fund (UNFPA) sponsored a conference in Nairobi, Kenya that launched the Global Safe Motherhood Initiative. ${ }^{37}$ Its aims were to raise awareness of the neglected problem of the world's approximately half a million annual maternal deaths, nearly all of which occurred in developing countries, to spark efforts to address this problem, and to reduce maternal mortality levels by half by the year 2000. Following the conference an Inter-Agency Group for Safe Motherhood (IAG) formed to focus global 
attention on the issue, grouping a number of international agencies and non-governmental organizations involved in the launch. Since this conference two decades ago, safe motherhood advocates have engaged in a sustained effort to convince international organizations and national political leaders to prioritize maternal mortality reduction.

Nearly all respondents perceive the initiative’s results in producing political support to have been disappointing. Many published accounts on the initiative also come to the same conclusion. ${ }^{29,38-39}$ This being said, a number of respondents believe that the twentieth anniversary year of the initiative, 2007, offers an opportunity to generate political momentum for safe motherhood.

\section{Actor Power}

For much of the initiative’s history the policy community has been fragmented surrounding differences on intervention strategy, a situation that has affected its credibility with international and national political leaders (interviews no. 3, May 2006; no. 9, June 2006; no. 15, June 2006). Through the 1970s and 1980s antenatal risk screening and the training of traditional birth attendants formed the core strategies for maternal survival. ${ }^{28}$ An influential 1985 Lancet article expressed concern about these strategies, arguing that most maternal deaths could not be prevented and that women

needed access to emergency obstetric care in the event of complications at childbirth. ${ }^{40}$ While not denying the need for emergency obstetric care, other advocates emphasized that its importance had been exaggerated (interview no. 2, June 2005) and that community-level and preventative activities had critical roles to play. Some came to embrace what has been termed the 'skilled attendance' approach. Its core message, expressed at safe motherhood's tenth anniversary conference in 1997 in Sri Lanka, was to ensure skilled attendance at delivery, defined as, "having a health worker with midwifery 
skills present at childbirth, backed up by transport in case emergency referral is required" (p. ii). ${ }^{41}$

Participants in the debates indicate the disagreements were more than technical; they took on a personal quality. One respondent commented:

[People became] extremely defensive about their ideas...If you didn't agree with the idea you were bad and wrong...It was kind of like President Bush. If you are against this idea then you are a traitor (interview no. 2, June 2005).

Another described the whole history of the initiative to be "one of competing camps" (interview no. 3, May 2006). A third perceived that positions became deeply entrenched and nearly immutable:

We always know the answer. First TBAs and antenatal care, then that doesn't work so skilled attendants and emergency obstetric care... There is view bias. [You must] take the company line (interview no. 6, May 2006).

A 2006 Lancet series on maternal survival called for deliveries to be attended by midwives in health centers with other medical professionals present and higher levels of care available. ${ }^{42}$ The series reflected a consensus that had been building gradually in part of the policy community concerning the need to have both skilled attendance at birth and emergency obstetric care if needed. Many respondents noted a significant decrease in tension in the policy community, due in part to this emerging consensus (interviews no. 4, May 2006; no. 5, May 2006; no. 6, May 2006; no. 7, June 2006; no. 8, June 2006; no. 15, June 2006). This agreement did not encompass all members of the policy community, however. Some expressed strong concern about what to do in the interim, before such facilities could be set up, given resource scarcity and the difficulty poor countries faced in expanding care. ${ }^{43}$

Weak guiding institutions also contributed to policy community fragmentation and hindered the acquisition of political support. The IAG grouped effective individual advocates for safe motherhood and well-respected researchers. However, it included technical officials in the represented agencies rather than their senior leaders, hampering 
its ability to develop global political support for maternal mortality reduction. ${ }^{39}$ Also, controversy surrounded membership. IAG members made a deliberate decision initially to remain small. One founding member explained the rationale for this:

A lot of groups wanted to be in and the IAG was not perfect but worked well together...The group felt strongly that smaller was better. It was easier when dealing with difficult issues [such as] abortion (interview no. 21, August 2006).

Another initial IAG member commented that this decision was problematic, noting that, “we were accused, rightly so, of being a small inside group” (interview no. 23, September 2006). A non-member articulated one of the consequences of this decision: "the IAG was not and never was perceived as a strong mouthpiece for safe motherhood until much later” (interview no. 9, June 2006).

Another issue on guiding institutions, one the IAG was not able to resolve, concerned relationships among UN agencies. On other health issues such as child survival (UNICEF), family planning (UNFPA), and technical advice (WHO), a clear lead UN agency has existed. Such agency leadership in the UN system never developed for safe motherhood. ${ }^{30}$ UNICEF, UNFPA, WHO and the United Nations Development Program (UNDP) each developed safe motherhood activities, often run independently of one another. At certain points, the agencies were antagonistic, differing on intervention approach and competing for scarce safe motherhood resources (interviews no. 7, June 2006; no. 10, June 2006; no. 11, June 2006; no. 17, July 2006). One respondent from the UN involved in safe motherhood saw the core problem as a lack of UN agency ownership:

UNICEF was involved but children are its bread and butter...UNFPA was neither here nor there...It had advocacy and policy but not programs. The WHO balances between norms and standards and implementation - back and forth - it deals with many things. So safe motherhood doesn't have a home in the United Nations and that's a big problem (interview no. 10, June 2006).

Between 2002 and 2005, pressured by donors who did not want to fund separate efforts (interview no. 7, June 2006), the IAG and the Safe Motherhood Initiative it guided 
gradually merged with other initiatives to become a broader Partnership for Maternal, Newborn and Child Health. The idea of continuum of care was intuitively appealing to some of the organizations and actors involved, as it sought to ensure that the health of newborns, children and mothers would be promoted in a synergistic way (interviews no 18, July 2006; no. 23, September 2006). The idea and birth of the Partnership were contentious, however, and since its launch its leaders have had to manage tensions among its members (interviews no. 3, May 2006; no. 5, May 2006; no. 7, June 2006; no. 9, June 2006; no. 15, June 2006; no. 18, July 2006; no. 23, September 2006). The alliance between safe motherhood and newborn survival has been uneasy, and that between safe motherhood and child survival even more so. One point of contention concerns differences on facility versus community/home-based delivery. In addition, many child survival advocates have been wary of politically contentious discussions surrounding unsafe abortion, a leading cause of maternal mortality. Underlying these tensions has been a concern over the division and control of scarce resources. Commenting on the place of safe motherhood amidst these partnership tensions, one respondent said:

There are three siblings. Child survival is older, richer, more resourceful. The newborn is weak, small, but got a new grant from Gates for $\$ 60$ million. It is the small child in the family that everyone looks to. Safe motherhood is the middle child; it doesn’t know exactly where to be. We need a good parent to take care of the three equally - or unequally: safe motherhood needs more vigorous opportunities (interview no. 10, June 2006).

Supporters of the Partnership argue that the cause of maternal survival rightly belongs under its fold, integrated with child and newborn health (interview no. 23, September 2006). A number of safe motherhood advocates are suspicious, wondering whether the Partnership ultimately will serve the cause of maternal survival (interviews no. 3, May 2006; no. 9, June 2006; no. 16, June 2006; no. 17, July 2006). One notes that with the emergence of the Partnership many in the safe motherhood community are no longer sure if a safe motherhood initiative still exists. 
Weak mobilization of civil society organizations has also hindered the acquisition of political support. The White Ribbon Alliance formed in 1999 with the aim of promoting cross-national advocacy for safe motherhood, linking civil society institutions with donor and other organizations. However, few grassroots organizations concerned with the global dimensions of the issue have emerged. One reason may be the lack of access to the political process on the part of those most directly affected by this issue, poor women with little education, who face significant gender discrimination in many poor countries. Several respondents note also the initiative's detachment from those grassroots activities that do exist (interviews no. 9, June 2006; no. 10, June 2006; no. 15, June 2006). One commented:

There's a huge disjuncture. 35,000 feet discussions. And I'm worried the gap is getting bigger. International discussions are devoid of reality on the ground (interview no.15, June 2006).

A widely embraced leader may have helped surmount historical problems of policy community fragmentation, weak guiding institutions and minimal civil society mobilization. However, no such figure emerged (interviews no. 5, May 2006; no. 15, June 2006). Several individuals involved in the initiative at particular junctures were perceived potentially to have this capacity, but they did not take up the opportunity. Referring to child survival's best-known champion, one respondent put it as follows: “Safe motherhood doesn't have a Jim Grant. Where’s the ambassador?” (interview no. 15, June 2006).

\section{Ideas}

Finding a resonating set of ideas - positioning the issue publicly in ways that attract political support - has been a persistent problem for the initiative. Since the initiative's launch, a number of political leaders in developing countries have come to

perceive maternal mortality as an issue deserving of attention and resources. ${ }^{33,36,44}$ 
However, they have been few and far between, particularly in comparison to the many national leaders that have prioritized issues such as child survival and HIV/AIDS.

Safe motherhood advocates have made concerted efforts to develop frames for the issue that might resonate. They have emphasized the severity of the issue, made rightsbased arguments, connected the issue to economic outcomes and noted the effects on children. ${ }^{45-46}$ Despite these efforts, no frame has convinced large numbers of political leaders, a situation that continues to puzzle many members of the policy community. As one respondent puts it:

Why is it like this? Why have we not seen the flow of resources to do something about it? The issue has all the emotional appeal on so many different levels. The case can be made economically, in terms of household productivity, the next generation of children. What more do you need to capture the imagination? I don't understand it (interview no. 15, June 2006).

The initiative’s initial positioning may have contributed to difficulties in attracting political support from one group that might otherwise have lent powerful backing to the cause: the women's movement. When World Bank officials first came up with the idea for an international conference on maternal mortality in 1985, they were conscious of the Reagan administration’s unwillingness to support family planning internationally. Sensitive to the U.S. administration's conservatism on reproductive issues, Bank officials wanted to find, in the words of one of the organizers, "a concept that is politically unassailable, a name that brings in money, that makes a lot of people heroes, something the American administration cannot oppose” (interview no. 22, August 2006). From these deliberations the term 'safe motherhood' was borne. The organizers coalesced surrounding the term, in part because they perceived it was unlikely to incite active opposition from the administration. However, as one respondent put it: "The feminists 
didn’t like the term ‘safe motherhood' so [the issue] was never picked up by women's groups” (interview no. 7, June 2006). ${ }^{\text {iii }}$

The framing of the issue inside the policy community also has posed difficulties. At a fundamental level, the community has unified surrounding a shared belief that maternal mortality is a neglected tragedy that demands redress. This idea was the source of influence behind an article that helped bring international attention to the issue. The 1985 piece in the Lancet by Allan Rosenfield, considered by many to be cause's most effective champion, and Deborah Maine, highlighted the neglect of maternal survival in favor of child health. ${ }^{40}$ However, beyond this core point of agreement, the policy community until recently has had difficulty identifying unifying ideas. An internally resonating frame would require clear answers to a number of issues, none of which the policy community has yet to resolve in full, including: whether maternal mortality is the focal concern or maternal health more broadly; how progress should be measured; whether to embrace the continuum of care idea as the core positioning of the issue; the precise strategies to address the problem; and the relationship of the initiative to other health concerns, including family planning, the broader reproductive health agenda, and health systems development.

\section{Political Contexts}

Advocates have sought to build a favorable global political environment for safe motherhood by organizing international meetings and events on maternal mortality

\footnotetext{
iii The same respondent notes that many men, too, may have been reluctant to engage the issue, but for a different reason, arguing: "The neglect of women's issues...does reflect some level of unconscious bias against women at every level, from the community to high-level decision-makers... While we may ignore it, maternal health does involve sex and sexuality; it is bloody and messy; and I think many men (not all, of course) have a visceral antipathy for dealing with it.”
} 
reduction, seeking inclusion of the issue in other global meetings, and aiming to take advantage of policy windows such as that associated with the MDGs (interviews no. 7, June 2006; no. 18, July 2006; no. 19, August 2006; no. 21, August 2006; no. 22, August 2006; no. 23, September 2006). The impact of their efforts is uncertain. As AbouZahr has argued in a review of the history of the initiative, 'These efforts have lacked conviction', noting that, "safe motherhood meetings tend not to attract the most senior decision-makers." 39

The first efforts to promote maternal mortality reduction occurred in 1985 prior to the launch of the initiative, at the end of the UN Decade for Women, when women's rights advocates identified maternal mortality reduction as one among several issues that might sustain the women’s agenda (interview no. 21, August 2006). The 1987 Nairobi conference was the first major international event on safe motherhood. Safe motherhood also made the agenda of the Third International Conference on Population and Development in Cairo in 1994 and the Fourth World Conference on Women in Beijing in 1995. ${ }^{47}$ In 1997, a conference in Colombo, Sri Lanka marked the tenth anniversary of the initiative and in 1999 new initiatives and programs for maternal mortality reduction formed, including Columbia University’s Averting Maternal Death and Disability Program. This program received \$50 million from the Gates Foundation, the largest grant to date for safe motherhood.

A policy window - a favorable confluence of events providing an opportunity for advocates to press political leaders - opened for safe motherhood in 2000. In that year United Nations member states announced the Millennium Development Goals (MDGs), a set of poverty alleviation objectives for the year 2015. Maternal health was one of a select group of health goals to make the MDGs, goal number five being the reduction of the global maternal mortality ratio by 75 percent over 1990 levels by the year 2015 . 
It is not clear that the maternal health MDG, efforts by advocates to take advantage of the MDG, and ongoing global safe motherhood advocacy efforts have had significant impact on political support and resources. A weak global governance structure for health (including lack of leadership on the issue of safe motherhood within the UN system) has hampered the capacity of the initiative to create and take advantage of opportunities. On the positive side, influenced by the MDGs the United Kingdom's Department for International Development (DFID) increased maternal and newborn health funding from $£ 0.9$ million in 2001-02 to $£ 16.2$ million in 2005-06. ${ }^{48}$ Other donors also increased funding for maternal survival over this time period. ${ }^{48}$ Also, the MDG commitment stood behind several significant global calls for action, including a declaration in 2005 in New Delhi, India from UN agency heads and many developing country governments calling for global progress on maternal, newborn and child health. ${ }^{49}$ In addition, the leaders of the countries that rank number one and two in numbers of maternal death, India’s Prime Minister Manmohan Singh and Nigeria’s former President Olusegun Obasanjo, commented publicly on the maternal health MDG, expressed alarm about their countries’ high levels of maternal death, and demanded that their governments act to address the issue. ${ }^{35-36}$ This being said, several studies reveal ongoing significant global resource gaps for maternal health..$^{50-52}$ One study estimated an additional \$1 billion to meet maternal health needs in $2006^{50}$ and another identified a need for a yearly average increase of $\$ 3.9$ billion over ten years at a minimum to meet combined maternal and newborn health needs. ${ }^{52}$ Also, only a handful of developing countries have made maternal mortality reduction a significant political priority since the initiative's launch. ${ }^{1}$

The initiative’s twentieth anniversary year, 2007, may present new opportunities for generating political priority for safe motherhood. In February, Immpact, a maternal mortality research initiative, disseminated results from several years of studies on measurement strategies and program evaluation. In September, a Norwegian 
government-led initiative to accelerate progress toward the achievement of the child and maternal survival MDGs is due to be launched. The culminating event is the Women Deliver conference to be held in October to mark the initiative's twentieth anniversary. Heads of state, ministers of planning and finance, and other senior political officials have made commitments to attend, creating the potential for the meeting to bring about the high-level political support for the issue that has been lacking in the past.

\section{Issue Characteristics}

Three characteristics of the issue itself have made it difficult for maternal mortality to attract political support. Maternal deaths are not as numerous as those caused by a number of other high burden conditions, accurate measurement of maternal mortality is difficult technically, and the interventions to avert maternal death are not as simple as those for some other conditions.

The most recent estimate of the number of annual maternal deaths globally is 529,000 for the year $2000 .^{53}$ While high, this figure is much lower than the annual number of deaths from HIV/AIDS (2.9 million), tuberculosis (1.6 million) and malaria (1 million), as well as the number of deaths among children under five (10.6 million), and newborns (4 million). ${ }^{54-58}$ Many safe motherhood advocates are acutely aware of these figures (interview no. 5, May 2006; no. 15, June 2006) and have debated whether maternal health advocacy should instead emphasize other indicators of severity, such as morbidity, lifetime risk of death, or combined maternal and newborn deaths (which total 4.5 million).

In addition, maternal mortality is more difficult to measure than other health outcomes such as infant mortality, child mortality and fertility. ${ }^{59}$ The relatively low numbers of maternal deaths in any given geographic locality mean that confidence intervals for estimates from most survey methodologies are large, making it difficult both 
to ascertain actual levels and to determine whether change has occurred across time. These difficulties have led some researchers and programmers to turn to process indicators to evaluate impact and measure progress. Other researchers, while not denying the need for such indicators, emphasize the importance of continuing to find better ways to measure maternal mortality itself. ${ }^{60}$

Another problem is that the interventions necessary to prevent maternal death are not as simple as those for other conditions, such as certain vaccine-preventable diseases. Few of the leading maternal health epidemiologists believe that a magic bullet is available, and most argue that functioning health systems are critical. ${ }^{42,61}$ Disagreement exists on the actual degree of complexity of the necessary interventions, the strength of the evidence base for these interventions and their cost (interviews no. 2, June 2005; no. 3, May 2006; no. 6, May 2006; no. 7, June 2006; no. 12, June 2006; no. 15, June 2006). ${ }^{62,63}$

Several respondents indicate that the sometimes contentious public discussions surrounding measurement and evidence have had adverse effects on the initiative's ability to acquire political support and resources, and have contributed to policy community fragmentation:

We hang out our dirty washing. Other people are more discreet (interview no. 15, June 2006).

We don't know what's effective. We can't measure outcomes very well (interview no. 3, May 2006).

We focus on uncertainties. That is the truth but it will not convince the Minister of Finance (interview no. 15, June 2006).

I would go with my ideas [to a donor] and [X] would go with hers and who was to say who was correct (interview no. 9, June 2006).

These problems notwithstanding, safe motherhood advocates have used estimates, however imprecise, to generate attention for the cause. For instance in the mid-1980s Robert Cook of the World Health Organization sponsored studies that produced the first 
estimate of global maternal mortality levels: half a million maternal deaths annually. ${ }^{64}$ This figure drew the attention of international agency heads and others key to the initiative’s inception. ${ }^{30,39}$ Revised estimates from UN agencies in the mid-1990s provoked discussion between national leaders and UN agencies surrounding the issue, and may have increased maternal mortality’s profile with donor institutions. ${ }^{39}$

\section{DISCUSSION}

\section{Factors shaping global political priority for safe motherhood}

If we consider each of the four categories of factors that influence the acquisition of global political support, we see that the safe motherhood initiative has faced many adverse conditions. With respect to actors, the global policy community has been fragmented, no powerful guiding institutions emerged to guide the initiative, and organizational rivalries persisted throughout its history. In addition, while the initiative included highly capable individuals, it never coalesced surrounding a recognized leader. Also, the primary victims of maternal mortality, poor women in the developing world, have little political power and are disadvantaged by gender inequities, and civil society mobilization to make this cause a global priority has been weak. With respect to ideas, the global policy community has not yet found an internally resonating frame, and still struggles to find external frames that will move political leaders to action. With respect to political context, global policy windows have opened, but it is not clear how well the policy community has taken advantage of these. Also, the fragmented global structure of governance for health has made it difficult for safe motherhood to find an institutional home. With respect to issue characteristics, the severity of the problem is low compared to other conditions if indicated by mortality levels, hampering resource acquisition and 
mobilization efforts. Measurement is an ongoing problem and no widely accepted and simple way to monitor progress has emerged. Interventions are not simple, the evidence base for these is weaker than for some other issues, and the policy community has had trouble developing consensus on which interventions should be prioritized. Because of these adverse conditions, some due to the nature of the issue and others due to the decisions of the actors, even after twenty years the safe motherhood initiative remains in a state of infancy.

\section{Building global political priority for safe motherhood}

This being said, 2007 could present a window of opportunity to generate political support for the cause. Cohesion is building in the policy community as proponents of skilled attendance and emergency obstetric care bridge their differences. A major policy window has opened, prompted by the Millennium Development Goals and the twentieth anniversary of the initiative. In addition, the Partnership for Maternal, Newborn and Child Health may provide a new coordinating mechanism for global leadership on the issue.

Creating political momentum will require addressing four connected political challenges, in addition to ongoing technical challenges surrounding intervention and measurement. First is building on the growing cohesion in the policy community so that it can speak with authority and unity to international and national political leaders. Second is creating enduring guiding institutions to sustain the initiative. The Partnership may provide a platform, but given its recent creation and tensions among the policy communities that compose it, it is too early to make an assessment. Third is finding external frames that resonate and will convince political leaders they should be concerned about the issue. Policy community members have offered a number of ideas on framing, but none has taken hold widely. Fourth is building stronger linkages with national 
initiatives and mobilizing country-level civil society organizations. The dearth of such linkages and weak social mobilization for the cause in countries with high maternal mortality have hampered the acquisition of global political support.

\section{Future research on political priority for global health initiatives}

The larger question is why some global health initiatives attract political priority while others remain neglected. Our investigation, grounded in a synthesis of research on collective action and one case study, represents only a start in examining this complex issue. Further study and refinement of the framework is needed, ideally through comparisons across global health initiatives that vary in levels of political support. Such studies would have considerable value both for theory development and for practice. Empirically-grounded explanations on issue ascendance and neglect would advance our knowledge of global health agenda-setting dynamics. Equally importantly, they would offer guidance to struggling global health initiatives such as safe motherhood on how to generate needed political support. 


\section{ACKNOWLEDGEMENTS}

The authors are grateful to the MacArthur Foundation for funding this study. The first author also thanks the Center for Global Development for providing a visiting fellow position during which research was conducted and results written up. The authors also appreciate the many individuals who agreed to be interviewed for this research. They were generous and candid with their insights, information and time, and it would have been impossible to conduct this study without their openness. Finally, the authors thank Ben Elberger for his thoughtful comments on drafts, and his research support for this work. The views presented represent those of the authors alone, who take responsibility for all errors. 


\section{References}

1 Shiffman J. Generating political priority for maternal mortality reduction in 5 developing countries. Am J Public Health 2007; 97: 796-803.

2 Keck ME, Sikkink K. Activists beyond Borders: Advocacy Networks in International Politics. Ithaca and London: Cornell University Press, 1998.

3 Finnemore M, Sikkink K. International Norm Dynamics and Political Change. International Organization 1998; 52: 887-917.

4 Finnemore M, Sikkink K. Taking stock: the constructivist research program in international relations and comparative politics. Annu Rev Polit Sci 2001; 4: 391416.

5 Haas PM. Introduction: epistemic communities and international policy coordination. International Organization 1992; 46: 1-35.

6 Florini AM. The Third Force: The Rise of Transnational Civil Society. Washington, DC: Carnegie Endowment for International Peace, 2000.

7 McAdam D, McCarthy JD, Zald MN. Preface. In: McAdam D, McCarthy JD, Zald MN, eds. Comparative perspectives on social movements: Political opportunities, mobilizing structures, and cultural framings. Cambridge: Cambridge University Press, 1996.

8 Tarrow S. Power in Movement: Social Movements, Collective Action and Politics. 2nd ed. New York: Cambridge University Press, 1998.

9 Johnston H, Noakes JA. Frames of Protest: Social Movements and the Framing Perspective. Lanham, MD: Rowman \& Littlefield Publishers, Inc., 2005.

10 Snow DA, Rochford Jr. EB, Worden SK, Benford RD. Frame alignment processes, micromobilization, and movement participation. American Sociological Review 1986; 51: 464-81 
11 Sabatier PA. The advocacy coalition framework: revisions and relevance for Europe. Journal of European Public Policy 1998; 5: 98-130.

12 Kingdon JW. Agendas, alternatives and public policies. Boston: Little, Brown and Company, 1984.

13 Baumgartner FR, Jones BD. Agendas and Instability in American Politics. Chicago: The University of Chicago Press, 1993.

14 Buse K, Mays N, Walt G. Making Health Policy. Maidenhead: Open University Press, 2005.

15 Reich, MR. The politics of health sector reform in developing countries: three cases of pharmaceutical policy. Health Policy 1995; 32: 47-77.

16 Brugha R, Varvasovszky Z. Stakeholder analysis: a review. Health Policy Plan 2000; 15: 239-46.

17 Berman S. Review: ideas, norms and culture in political analysis. Comparative Politics 2001; 33: 231-50.

18 Harris PG, Siplon PD. The Global Politics of AIDS. Colorado: Lynne Rienner Publishers, Inc., 2007

19 Prins G. AIDS and global security. International Affairs 2004; 5: 931-52.

20 Leichter HM. A Comparative Approach to Policy Analysis: Health Care Policy in Four Nations. Cambridge: Cambridge University Press, 1979.

21 Grindle M, Thomas J. Public Choices and Policy Change: the Political Economy of Reform in Developing Countries. Baltimore: Johns Hopkins University Press, 1991.

22 Walt G, Gilson L. Reforming the health sector in developing countries: the central role of policy analysis. Health Policy and Planning 1994; 9: 353-70.

23 Gourevitch, P. The second image reversed: the international sources of domestic politics. International Organization 1978; 32: 881-912. 
24 Walt, G. Global Cooperation in International Public Health. In International Public Health. Merson MH, Black RE, Mills AJ, eds. Gaithersberg, MD, USA: Aspen Institute, 2001.

25 Lee K, Collinson S, Walt G, Gilson L. Who should be doing what in international health: a confusion of mandates in the United Nations? Brit Med J 1996; 312: $302-7$.

26 Stone, DA. Causal stories and the formation of policy agendas. Political Science Quarterly 1989; 104: 281-300.

27 Yin R. Case Study Research: Design and Methods. 2nd ed. Thousand Oaks, California: Sage, 1994.

28 De Brouwere V, Tonglet R, Van Lerberghe W. Strategies for reducing maternal mortality in developing countries: what can we learn from the history of the industrialized West? Trop Med Int Health 1998; 3: 771-82.

29 Maine D, Rosenfield A. The Safe Motherhood Initiative: why has it stalled? Am J Public Health 1999; 89: 480-2.

30 Starrs AM. Safe motherhood initiative: 20 years and counting. Lancet 2006; 368: 1130-32.

31 Hay C. Dying mothers: Maternal mortality in rural Indonesia. Medical Anthropology 2000; 18: 243-79.

32 Shiffman J. Generating political will for safe motherhood in Indonesia. Soc Sci Med. 2003; 56: 1197-1207.

33 Shiffman J, Stanton C, Salazar AP. The emergence of political priority for safe motherhood in Honduras. Health Policy Plan. 2004; 19: 380-390.

34 Shiffman J, Garcés Del Valle AL. Political history and disparities in safe motherhood between Guatemala and Honduras. Popul Dev Rev. 2006; 32: 53-80. 
35 Shiffman J, Okonofua FE. The state of political priority for safe motherhood in Nigeria. Br J Obstet Gynaecol. 2007; 114: 127-133.

36 Shiffman J, Ved RR. The state of political priority for safe motherhood in India. Br J Obstet Gynaecol. 2007; 114: 785-790.

37 Starrs, A. Preventing the Tragedy of Maternal Deaths: A Report on the International Safe Motherhood Conference. New York: Family Care International, 1987.

38 Weil O, Fernandez H. Is safe motherhood an orphan initiative? Lancet 1999; 354: 940-3.

39 AbouZahr C. Cautious champions: International agency efforts to get safe motherhood onto the agenda. Studies in Health Services Organisation \& Policy 2001; 17: 384-411.

40 Rosenfield A, Maine D. Maternal mortality--a neglected tragedy. Where is the M in MCH? Lancet 1985; 2: 83-5.

41 Starrs A, on behalf of the Safe Motherhood Inter-Agency Group. The Safe Motherhood Action Agenda: Priorities for the Next Decade. Colombo, New York: Family Care International, 1998.

42 Campbell OM, Graham WJ. Strategies for reducing maternal mortality: getting on with what works. Lancet 2006; 368: 1284-99.

43 Costello A, Azad K, Barnett S. An alternative strategy to reduce maternal mortality. Lancet 2006; 368: 1467-9.

44 Campbell O, Gipson R, Issa AH, Matta N, El Deeb B, El Mohandes A et al. National maternal mortality ratio in Egypt halved between 1992-93 and 2000. Bull World Health Organ 2005; 83: 462-71.

45 Freedman LP. Using human rights in maternal mortality programs: from analysis to strategy. Int J Gynaecol Obstet 2001; 75: 51-60. 
46 Filippi V, Ronsmans C, Campbell OM, Graham WJ, Mills A, Borghi J et al. Maternal health in poor countries: the broader context and a call for action. Lancet 2006; 368: 1535-41.

47 Campbell O. What are maternal health policies in developing countries and who drives them? A review of the last half-century. Studies in Health Services Organisation \& Policy 2001; 17: 415-45.

48 Department for International Development. DFID’s Maternal Health StrategyReducing Maternal Deaths: Evidence and Action, Second Progress Report. London: Department for International Development, 2007.

49 The Delhi Declaration on Maternal, Newborn, and Child Health. Delhi, 2005. http://www.internationalmidwives.org/modules/ContentExpress/img_repository/D elhi_Declaration_FINAL_10_April_05.pdf accessed December 1, 2006.

50 Borghi J, Ensor T, Somanathan A, Lissner C, Mills A. Mobilising financial resources for maternal health. Lancet 2006; 368: 1457-65.

51 Powell-Jackson T, Borghi J, Mueller DH, Patouillard E, Mills A. Countdown to 2015: tracking donor assistance to maternal, newborn, and child health. Lancet 2006; 368: 1077-87.

52 Johns B, Sigurbjörnsdóttir K, Fogstad H, Zupan J, Mathai M. Estimated global resources needed to attain universal coverage of maternal and newborn health services. Bulletin of the World Health Organization 2007; 85: 256-63

53 World Health Organization. Maternal Mortality in 2000: Estimates developed by WHO, UNICEF, and UNFPA. Geneva: World Health Organization, 2004.

54 UNAIDS. AIDS Epidemic Update: December 2006. Geneva: UNAIDS, 2006.

55 World Health Organization. Fact Sheet Number 104: Tuberculosis. Geneva: World Health Organization, 2007. 
56 Roll Back Malaria. World Malaria Report 2005. Geneva: Roll Back Malaria, WHO, UNICEF, 2005.

57 Bryce J, Boschi-Pinto C, Shibuya K, Black RE. WHO estimates of the causes of death in children. Lancet 2005; 365: 1146-52.

58 Lawn JE, Cousens S, Zupan J. 4 million neonatal deaths: When? Where? Why? Lancet 2005; 365: 891-900.

59 Stanton C, Abderrahim N, Hill K. DHS Maternal Mortality Indicators: An Assessment of Data Quality and Implications for Data Use. Calverton, Maryland, USA: Macro International, Inc, 1997.

60 Graham WJ. Now or never: the case for measuring maternal mortality. Lancet 2002; 359: 701-4.

61 Ronsmans C, Graham WJ. Maternal mortality: who, when, where, and why. Lancet 2006; 368: 1189-200.

62 Miller S, Sloan NL, Winikoff B, Langer A, Fikree FF. Where is the "E" in MCH? The need for an evidence-based approach in safe motherhood. J Midwifery Womens Health 2003; 48: 10-8.

63 Paxton A, Maine D, Freedman L, Fry D, Lobis S. The evidence for emergency obstetric care. Int J Gynaecol Obstet 2005; 88: 181-93.

64 World Health Organization. Maternal Health and Safe Motherhood Programme: Progress Report 1987-1990. Geneva: World Health Organization, 1990. 